Esta obra está sob o direito de Licença Creative Commons Atribuição 4.0 Internacional.

\title{
UMA REFLEXÃO SOBRE OS AVANÇOS NA EDUCAÇÃO INCLUSIVA: NOVAS PRÁTICAS NA FORMAÇÃO DOÇENTE
}

\author{
Maria Angela da Silva Alves ${ }^{1}$ \\ Aline Pereira Barros ${ }^{2}$ \\ Fabia de Oliveira Silva ${ }^{3}$ \\ Wilamo de Omena Lopes Junior ${ }^{4}$
}

\section{RESUMO}

Compreende-se por educação inclusiva a ascensão e conservação dos educandos nas escolas de ensino regular, de todas as camadas da educação independentemente de suas distinções ou carências individuais, de modo a proporcionar a aprendizagem e o desenvolvimento individual, respeitando as diferenças constantes ao homem, como assegura Mantoan (2006), incluir "de modo a reconhecer e valorizar as diferenças, sem discriminar os alunos nem segregá-los" (p.15). Há diversos documentos que garantem a educação inclusiva, dentre eles ressalva-se, em nível internacional, a Declaração de Salamanca, de 1994, que sugere que as crianças com necessidades educacionais especiais precisam possuir o direito a ascensão a escola regular, ao meio de uma pedagogia capaz de suprir suas necessidades. Do mesmo modo, todas as autoridades governamentais necessitam estarem em condições a abarcarem todas as crianças, independentemente de suas diferenças ou dificuldades individuais. O objetivo buscado é entender como se dá a educação inclusiva na prática, levando em consideração tantos respaldos que esta parcela populacional possui no papel. Para alcançar o objetivo buscamos livros, artigos e publicações que mostrassem esta realidade e alguns sucessos e avanços. Percebemos durante a pesquisa que diversos são os atos a tornarem a educação inclusiva uma medida produtiva e que muito falta para galgá-la.

Palavras-chave: Educação Inclusiva. Desenvolvimento. Respeito.

\footnotetext{
${ }^{1}$ Angelateache2@ hotmail.com

2 Aline_barros09@hotmail.com

${ }^{3}$ Fabia.oliveira1@gmail.com

${ }^{4}$ wiliamojr@msn.com
} 


\section{INTRODUÇÃO}

De acordo com Mazzotta (1996) a aflição no âmbito educacional dos indivíduos portadores de necessidades especiais em nosso país é nova. Tendo seu início efetivo no século XIX, embasado em experiências norte-americanas e europeias. A passagem permite ser repartida em quatro grandes etapas:

Até 1854 , os portadores de necessidades especiais, independente de qual natureza, se física, mental ou sensorial, eram abandonados quer pela família quer da sociedade, passando a ser acolhido por asilos e estabelecimentos filantrópicos e/ou religioso.

Geralmente perpassavam toda a existência isentos de qualquer atendimento especializado com a finalidade de capacitálo. Entre os anos de 1854 e 1956 inicia gradualmente o aparecimento de raras instituições de ensino especiais, particulares, com foco na assistência clínica especializada. Durante este período a sociedade começava a entender que os portadores de deficiência tinham a possibilidade de se tornarem produtivos, e a assistência foi aos poucos deixando de ser no âmbito da saúde para ser o educacional.

Entre 1957 a 1993 foi um período determinado por atos tanto oficiais como em âmbito nacional. A educação especial se instituiu como uma modalidade de educação, que garantia um pacote de atividades educacionais especiais, instituídos nas diversas instituições escolares, com o compromisso de: apoiar, complementar, suplementar e, em algumas situações, suprir as tarefas educacionais corriqueiras. A finalidade era assegurar o acesso à educação escolar formal e desencadear a capacidade dos educandos.

No ano de 1990, o Brasil participou da Conferência Mundial sobre Educação para Todos na cidade de Jomtien, na Tailândia, onde ficaram estabelecidos os iniciais prognósticos da política de educação inclusiva. A partir de 1994, o entendimento de educação inclusiva ficou no lugar da teoria de educação especial através da Declaração de Salamanca (UNESCO, 1994), que aumentou a teoria da necessidade educacional especial e acudiu a necessidade de inclusão dos educandos especiais no sistema regular de ensino, possuindo como slogan "Educação para Todos".

A sugestão da educação inclusiva se embasa no amoldamento curricular, que acontece por meio do ato de um grupo multidisciplinar que disponibiliza apoio quer ao educador quer ao portador de necessidades especiais, através de acompanhamento, estudo e pesquisa de maneira a fornecer a ascensão e a 
permanência na rede comum de ensino em qualquer que seja o nível.

A consolidação da escola induzida se respalda no amparo de princípios e valores éticos, nos ideais de cidadania e justiça, para todos, em contraposição aos sistemas hierarquizados de inferioridade e desigualdade. De acordo com SASSAKI (1997, p. 41) “inclusão é um processo pelo qual a sociedade se adapta para poder incluir em seus sistemas sociais gerais

\section{REFERENCIAL TEÓRICO}

\section{A formação de professores para a educação inclusiva}

De acordo com Morin (2004, p. 11) "uma educação só pode ser viável se for uma educação integral do ser humano. Uma educação que se dirige à totalidade aberta do ser humano e não apenas a um de seus componentes".

A educação necessita ajudar, não apenas na conscientização da nacionalidade, porém autorizar que esta signifique o desejo de atingir a cidadania plena terrena (MORIN, 2004, p. 18).

No instante em que se fala da inclusão, é necessário levar em consideração as características associadas a formação do educador, visto que, este necessita se encontrar capacitado e seguro para executar suas tarefas com o educando portador de necessidades educacionais pessoas com necessidades especiais e, simultaneamente, estas se preparam para assumir seus papéis na sociedade".

Abranger significa trocar, entender, respeitar, valorizar, lutar contra exclusão, ultrapassar obstáculos que o meio social instituiu para os indivíduos. É disponibilizar a ampliação da independência, através da ajuda de reflexão e construção de valor, dando a oportunidade de decisão, ou seja, o agir nas mais distintas ocasiões da vida. especiais. Piaget (1984, p. 62) já ressaltava que o preparo do educador significa demanda principal da totalidade das transformações pedagógicas, afinal, enquanto esta não for solucionada de modo aceitável, será integralmente inviável constituir programas ou edificar bonitos conceitos no tangente ao ser feito. Este tópico mostra dois ângulos. O primeiro, que há uma demanda social da valorização ou da revalorização dos educadores primário e secundário, onde suas atividades não possuem o valor a que fazem jus sequer pela opinião pública, onde a falta de interesse e a miséria que se fizeram presentes na profissão e que significam um imenso perigo para o desenvolvimento, e, por conseguinte para a sobrevivência da população doente. Dando prosseguimento, nos deparamos com a capacitação intelectual e moral do educador, moléstia bastante difícil de extinguir, afinal quão 
melhor for a metodologia determinado para a prática educacional, mais difícil se mostra a profissão do educador, que não imagina ensinar a apenas uma camada eletiva, porém exercer o seu ofício a todos.

Os três meios indicados por Perrenoud (2000) se instituem em feitios básicos para a constituição de profissionais que adotem a empreitada de desbravar e abrir novos caminhos, edificando deste modo, uma independência singular e comando na direção de sala de aula. Levando em consideração se tratar de profissional pensador, os produtos acabados não se adequam mais, porém as desenvolturas para identificar, definir, projetar, avaliar os desafios.

Conforme Paula (2004):

$\mathrm{Na}$ formação de professores de educação especial, essa ambiguidade manifesta-se, por exemplo, na forma como as políticas públicas consideram essa questão. Também fica evidente, na construção do saber e, do saber fazer, desses futuros docentes, pois os currículos de sua formação inicial privilegiam, predominantemente, a especificidade do trabalho com determinados alunos "especiais" por que apresentam incapacidades físicas, e/ou mentais, e/ou sensoriais, e/ou adaptativas". Tal como constata Bueno (1998) apud Nunes et al (1998, p. 70).

O curso universitário do educador especial foi incluso como desenvoltura da pedagogia a qual, normalmente, enxerga a formação docente como subproduto da especialização: configura-se nessa formação. Entretanto, um professor especializado, com mínima capacitação de educador, com experiência teórico-prático insuficiente. Servirá apenas como professor de ensino fundamental. $O$ destaque nas particularidades e problemas peculiares das diferentes carências iterou mais intensificamente uma "especificidade docente" que não considerou probabilidades aumentadas a respeito da relação sobre o fracasso escolar e o desenvolvimento pedagógico.

Bueno (1999) indica que para um ensino considerado de qualidade para educandos com necessidades especiais, no ponto de vista de um trabalho inclusivo, abrange no mínimo, duas modalidades de formação docente: educadores "coronelistas" do ensino regular, com um conhecimento mínimo e menor ainda a prática com educandos diversificados; e educadores nas distintas "necessidades educacionais especiais", quer para atender a essa camada de demandas quer para suporte as tarefas concretizadas pelos profissionais de salas regulares que esses alunos estejam integrados.

A atividade docente com portadores de necessidades educacionais especiais atualmente precisa em estar em culminância com dois aspectos: o profissional e o 
intelectual, e para tal é necessário da competência em elaborar novamente os conhecimentos.

Sendo assim, na duração da capacitação inicial, outras especialidades necessitam ser investigada como a construção, o conceito, a reinterpretação dos currículos e projetos que ofertem a capacitação, valorização e identificação do educador (PIMENTA, 2002, p. 131-132)

A profissionalização apropriada ocorre no instante em que se autoriza o educador a tornar racional e avaliar sua ação, criticando-a, revisando-a, fundamentando-a na edificação da ampliação da escola. O educador é um membro essencial no desenvolvimento da inclusão, porém ele necessita ter apoio e valor, afinal sozinho não é possível concretizar a edificação de uma instituição de ensino embasada num entendimento includente.

Desta maneira se torna indispensável necessário "a preparação de todo o pessoal que constitui a educação, como fator chave para a promoção e progresso das escolas inclusivas" (Declaração Salamanca, p. 27). E ainda "a provisão de serviços de apoio é de importância primordial para o sucesso das políticas educacionais inclusivas." (SALAMANCA, p. 31)
Conforme Mittler (2003, p. 35), “A inclusão implica que todos os professores têm o direito de esperar e de receber preparação apropriada na formação inicial em educação e desenvolvimento profissional contínuo durante sua vida profissional".

\section{A flexibilização do ensino}

A inclusão de educandos com algum tipo de deficiência, que se mostram com necessidades educacionais especiais na sala de aula do ensino regular, demonstrou que a tarefa pedagógica clássica, embasada somente a transferência de conhecimento, é insuficiente para ensinar a maioria dos educandos.

$$
\text { Conforme Blanco (2004), a }
$$
instituição de ensino, classicamente, focou em suprir as carências comuns, refletindo objetivos sem levar em consideração as características singulares de cada educando.

Essa conduta tradicional, no espaço curricular, fica exposta por propostas rigorosas e homogêneas, que ignoram os variados moldes responsáveis pelo desenvolvimento do ensino e aprendizagem. Como sequela, é permitido detectar o grande acontecimento de baixa aprendizagem, repetências, absenteísmo e fracasso escolar (BLANCO, 2004).

A atividade de inclusão escolar mostrou que a educação, através de suas 
metodologias clássicas, retira do meio social e educacional um número de educandos cada vez maior, onde deveria ser o contrário (FREITAS, 2006). Deste modo, foi ressaltando que levar em consideração as características de cada educando é essencial para assegurar nível de ensino para todos os educandos, e não somente para os que mostram mais claramente suas necessidades.

Recordamos que os educandos em sua totalidade possuem características físicas, comportamentais e emocionais singulares, porém por adotar uma sistemática homogênea não torna possível a aprendizagem a todos.

Para Perrenoud (2001), a maior parte das táticas de ensinos colocadas em prática pelo educador precisa ser adaptada as características do educando, à composição da classe e a história das relações entre os educandos e entre eles e o professor.

Por este motivo, se torna nítida a relevância da concretização de adaptação curricular para que ocorra a inclusão do educando com necessidades educacionais especiais, em especial para os que mostram deficiência mental.

O Brasil precisa promover um currículo que assegure não somente a ascensão, porém a permanência na instituição de ensino regular e o êxito do educando com deficiência estão disponibilizados no documento denominado de Parâmetros Curriculares Nacionais - PCN, Adaptações Curriculares em ação, construído pela Secretaria de Educação Especial, do Ministério da Educação, homologado originalmente em 1999 e reeditado em 2002.

De acordo com este documento, as adaptações curriculares necessitam ser compreendidas como um processo a ser realizado em três níveis:

- no projeto político pedagógico da escola, por meio do qual é possível identificar e analisar as dificuldades enfrentadas pela escola assim como estabelecer objetivos e metas comuns aos gestores, professores, funcionários da escola, familiares e alunos;

- no currículo desenvolvido em sala de aula;

- no nível individual, por meio da elaboração e implementação do Programa Educacional Individualizado (PEI).

$\mathrm{Na}$ proposta educacional inclusiva o currículo deve ser ajustado também da ideia da diferença e não é o aluno que se ajusta, se adapta as condições de ensino, mas a leitura do movimento da inclusão educacional é justamente contrária, é a 
equipe escolar que tem que prover as mudanças necessárias para que o aluno consiga acessar o currículo (ARANHA, 2003).

\section{As diferentes necessidades}

Nos dias atuais, a inclusão é um tema que aparece com frequência no meio educacional e na mídia, porém não tem sido fácil pensar em meios que favoreçam a inclusão de crianças, jovens e adultos no contexto escolar e no meio social em geral. As limitações dentro da escola e no convívio social para portadores de necessidades especiais são inúmeras e com ela a falta de conhecimento e oportunidade de inserir numa sociedade que prega igualdade para todos.

Pensando na educação especial observamos uma forma enriquecida da educação geral, pois possui as mesmas finalidades e objetivos. Sendo assim, tais objetivos consistem em prestar assistência às crianças, jovens e adultos portadoras de necessidades educacionais especiais, preparando-as para a vida e integrando-as à comunidade, a fim de que se tornem pessoas úteis e produtivas à sociedade.

É impossível apoiar-se no que falta a sua criança, naquilo que ela não é. Torna-se necessário ter uma ideia, ainda que seja vaga, sobre o que ela possui sobre o que ela é (VYGOTSKY apud MONTEIRO, 1989, p. 102).
Deve-se reconhecer que a deficiência possui uma dupla influência no desenvolvimento, que se por um lado atua como limitação, criando obstáculos, prejuízos e dificuldades, por outro serve como estímulo para o desenvolvimento das vidas de adaptação, canais de compreensão.

Assim, o atendimento a crianças portadoras de qualquer tipo de deficiência deverá ter início o mais cedo possível, isto claro, com a participação dos pais, que é fundamental, como igualmente, sua integração dinâmica com os profissionais, educadores e o meio em que vive. $\mathrm{O}$ empenho e o carinho representam o primeiro passo para uma pessoa diferente que veio ao mundo. Sem apoio doméstico não há autoestima e os obstáculos podem parecer insuperáveis.

Muitas das necessidades nem sempre são conhecidas pela família desses alunos que estão na escola apresentando quase sempre uma dificuldade no processo de aquisição do conhecimento. É preciso que a deficiência seja uma realidade para a família que nem sempre aceita a deficiência dificultando o processo de adaptação, de socialização e de comportamento dentro do contexto escolar.

As deficiências são apontadas como graves problemas, e a escola nem sempre tem a equipe de especialistas que possam acompanhar essa criança ou a família para 
orientações que fortaleçam o vínculo escola e família. É obrigação de todos os envolvidos buscaram soluções que viabilizem inserção dos portadores de necessidades especiais na sociedade e em especial na escola onde vão aprender a ser respeitados e a respeitar.

\section{A escola como espaço inclusivo}

A educação tem a tarefa de promover a apropriação de saberes, procedimentos, atitudes e valores por parte de alunos e é nesse sentido que se torna um ambiente de transformação social e tenta romper barreiras que limitam a sua capacidade de oportunizar a inclusão seja ela qual for.

Diante disso, é fato afirmar que a escola não deve ser depósito de criança, jovens ou adultos portadores de necessidades educacionais especiais, pois é dever da escola organizar sua estrutura curricular, seu projeto político pedagógico e sua equipe de professores que sejam capacitados pra atender alunos portadores de necessidades educacionais especiais.

Priorizar a socialização desses alunos e criar novas formas de articular teoria e prática na escola e em especial na sala de aula não é uma tarefa fácil, mas com compromisso e parcerias é possível oferecer uma escola formadora de cidadãos capazes de criar sua própria aprendizagem e interagir no meio social onde vivem.

Mazota (2002, p. 36) afirma que:

a efetivação da educação escolar
para todos, mediante recursos tais
como a educação especial,
preferencialmente na rede regular
de ensino, para os que requeiram
ou educação inclusiva onde a
diversidade de condições dos
alunos possa ser competente,
contemplada e atendida,
demandará uma ação
governamental pela sinergia, que
algumas vezes parece ser até
enunciada. Isso sem ignorar que a
verdadeira inclusão escolar e
social implica, essencialmente, a
vivência de sentimentos e atitudes
de respeito ao outro como cidadão.

A escola não deve ser negligente em sua atitude inclusiva, deve oportunizar o melhor e fazer desse desafio um sucesso para que a sua função social seja exercida com êxito. Criar e oferecer espaços para a inclusão é romper uma serie de preconceitos já traçados pela sociedade e pelos familiares que muitas das vezes não aceitam o fato de ter uma criança portadora de necessidades especiais, recebendo o primeiro rótulo. $\mathrm{O}$ papel fundamental da educação no desenvolvimento das pessoas e da sociedade amplia-se ainda mais no despertar das exigências atuais e aponta para a necessidade de se construir uma escola, com educação voltada para a 
formação de cidadão, quer seja no aspecto educacional ou profissional.

Vivemos uma sociedade que ao invés de incluir, exclui e a escola ao invés de assumir o seu papel e sua função.

É necessário apresentar uma postura e uma concepção político-pedagógica exigente e eficaz que fortaleça todo processo educativo de todos os alunos nos mesmos espaços educativos sem com isso favorecer uma presença de conceito excludente.

Um cidadão que apresenta qualquer tipo de deficiência é antes de tudo uma pessoa que merece respeito e compreensão e sua potencialidade oral, escrita, comunicativa, de qualquer que seja a forma, deve ser valorizada e compreendida como forma de tentativa para a inclusão social dentro da escola e conviver com a diferença é o desafio atual para professores e alunos considerados normais, pois é uma atitude de que requer muito diálogo e muito estudo para oferecer uma teoria que esteja vigente com a prática de inclusão.

A escola tem um papel significativo, não só para o desenvolvimento cognitivo e social das crianças, mas também para a sua saúde em geral, pois ela é o primeiro espaço social que vai promover a separação entre a criança e a família, estabelecendo um importante contato e um elo com a cultura. Priorizar a qualidade do ensino regular inclusivo é um desafio que precisa ser assumido por nossa sociedade, e pelos educadores, em particular, para que se coloque em prática o princípio democrático da educação para todos.

No Capítulo III, da Educação, da Cultura e do Desporto, Art. 205, a Constituição prescreve em seu art. 208, que o dever do Estado com a educação será efetivado mediante a garantia de "atendimento educacional especializado aos portadores de deficiência, preferencialmente na rede regular de ensino."

Nessa mesma linha de conduta, a Lei de Diretrizes e Bases da Educação Nacional - LDB n ${ }^{\circ}$ 9394/96 (BRASIL, 1996a), em seu Capítulo V, Art. 58, da Educação Especial, coloca que se deve entender "por educação especial, para os efeitos desta Lei, a modalidade de educação escolar, oferecida preferencialmente na rede regular de ensino, para educandos portadores de necessidades especiais." O atendimento especializado deve estar disponível em todos os níveis de ensino, de preferência na rede regular desde a educação infantil à universidade.

Por sua vez, o Estatuto da Criança e do Adolescente (BRASIL, 1996) também recomenda, em seu Art. 15, que "a criança e o adolescente tem direito a liberdade, ao respeito e a dignidade como seres humanos 
em processo de desenvolvimento" e, acrescenta no seu Art. 53, que "a criança e o adolescente têm direito à educação, visando ao pleno desenvolvimento de sua pessoa [...] assegurando-lhes a igualdade de condições para o acesso e permanência na escola".

É nessa perspectiva que se destaca a importância de estudos sobre a escola inclusiva enquanto contexto de desenvolvimento significativo não apenas para as crianças deficientes, mas também para crianças não deficientes, pela possibilidade da convivência com a diversidade e do estimulo a cidadania.

\section{Educação e inclusão}

Os questionamentos a respeito das consequências da educação possuem dois ângulos. Existe o impacto no que diz respeito à economia, e também a situação da equidade ou probidade social, onde independente do motivo é válida.

Em uma sociedade com economia tradicional, desde que minimamente aberta, uma pessoa talentosa e com iniciativa pode vencer na vida. Ao cabo de alguns anos, pode aprender um ofício; se for alfabetizado, pode abrir um pequeno negócio.

Contudo, a modernidade traz a necessidade de muito mais educação em praticamente todas as posições que estão acima do patamar inferior.

A sociedade brasileira já atravessou esse umbral de modernidade. A consequência é que, por meio da escolaridade, foram criados os mais variados filtros para o progresso individual. $\mathrm{O}$ acesso a melhores posições requer cada vez mais escolaridade. No mais das vezes, os filtros de escolaridade refletem necessidades reais no seu desempenho. Contudo, universaliza-se o paradigma de filtrar o acesso aos empregos pela escolaridade, mesmo para as ocupações que realmente prescindem dela. Lixeiro não precisa ir à escola para fazer seu trabalho. $\mathrm{Na}$ prática, entretanto, os concursos $\mathrm{o}$ exigem. Para o argumento aqui desenvolvido, o que interessa não são as razões para exigir escolaridade, mas o fato de que isso está acontecendo, e de forma cada vez mais generalizada.

O resultado desse processo é que os caminhos para o progresso individual sem escolaridade vão ficando cada vez mais estreitos. Para chegar próximo do topo, praticamente somente os esportes e as artes - ou a beleza - conseguem oferecer chances para quem não tem diplomas. Isso significa que, para a esmagadora maioria da população, sua renda será determinada pelo investimento feito em educação. De fato, segundo diversos estudos [ver, entre outros, 
Menezes-Filho (2001), Ferreira (2000) e Ramos e Vieira (2000)], cerca de 1/4 da disparidade de rendimentos no Brasil podem ser atribuídos aos diferenciais de educação, e essa proporção é ainda maior ao se considerar apenas o rendimento do trabalho.

Diante desse quadro, quem não consegue vencer as barreiras de acesso e de êxito dentro da escola está condenada a baixa mobilidade ocupacional e renda restrita.

Até pouco mais de uma década, havia um filtro já na entrada da escola, na forma de uma coorte maior do que o número de vagas. Na década de 1990, a entrada se universalizou e o filtro passou para dentro da escola fundamental, mais à semelhança dos demais países com acesso universal. Apesar disso, há muita desigualdade entre as crianças que vão para o fundamental, e isso ocorre mesmo em países ricos. Portanto, a questão não é perguntar se os pobres estão em desvantagem na escola desse ou daquele país, pois sabe-se que eles estão em desvantagem em todos - qualquer que seja seu regime político ou ideologia. A pergunta relevante é acerca do grau de desvantagem e do que se faz para reduzi-lo.

Nos países com escolas melhores, os pobres também estão em desvantagem, mas em grau muito menor. Nos países industrializados, praticamente todos conseguem terminar com sucesso dez anos de escolaridade, e com qualidade aceitável.

No Brasil, não apenas os mais pobres frequentam escolas piores, mas, mesmo quando estão nas mesmas escolas do que os menos pobres têm maiores dificuldades em aprender e avançar dentro do sistema. Ou seja, a escola é incapaz de oferecer a eles um aprendizado razoável e é, assim, incapaz de reduzir a desigualdade herdada dos pais. Tal como já indicado na edição de 2005 desta série, do ponto de vista de uma política de equidade, deve-se estabelecer como maior prioridade para a educação brasileira a melhoria da qualidade do ensino fundamental.

A agravar os problemas de acesso e de falta de qualidade da educação dos mais pobres estão as restrições econômicas. Quem tem mais renda pode frequentar escolas melhores, pode dedicar mais tempo aos estudos, tem acesso a livros, revistas, computador e internet, e recebe apoio adicional quando tropeça nos estudos.

No limite, um pobre talentoso que conseguisse passar no vestibular de medicina em uma universidade pública não poderia se sustentar durante o curso.

Daí a observação de que os poucos alunos de classe baixa que ingressam nas universidades públicas o fazem em cursos que não exigem grande comprometimento de tempo e dinheiro. Nesse aspecto, há um 
caráter eminentemente discriminatório no nosso ensino.

No ensino fundamental público, frequentado pelos mais pobres, os gastos por aluno são 1/10 do que o governo gasta com suas universidades, frequentadas predominantemente pelos $40 \%$ mais ricos.

Quando examinada a formação profissional, o quadro é mais favorável, ainda que também apresente problemas, como será visto adiante. O Sistema S5 oferece seus cursos de formação profissional gratuitamente para uma clientela de classe bem mais modesta. Já nos cursos técnicos e de tecnólogos privados, frequentados por alunos menos pobres na maioria dos casos, há cobrança de mensalidade. Ou seja, há um veio de progressividade desejável de ser encontrado em outros setores, o que raramente acontece. O principal aspecto negativo é ser o Sistema $\mathrm{S}$ relativamente pequeno para o tamanho da força de trabalho. Outra questão importante que milita contra a equidade do sistema é o fato de que, cada vez mais, os cursos profissionais pressupõem a alfabetização funcional por parte dos alunos, implicando que muitos fiquem de fora apenas por não atingirem o requisito mínimo para ler materiais didáticos e escrever as tarefas passadas pelo professor.

Como o analfabetismo funcional é muito elevado, atingindo, segundo algumas estimativas, 120 milhões de indivíduos, este é o número - ou algo próximo dele - dos que não terão acesso aos cursos técnicos, mesmo gratuitos.

Em resumo, houve uma gigantesca democratização no acesso e na permanência na escola acadêmica e no acesso a cursos oferecidos enquanto complemento. Do ponto de vista da equidade, também foi um grande salto. Mas há duas ressalvas. A primeira é que o país ainda está longe de um ensino que promova a equidade - hoje menos longe, é verdade, mas há ainda muito terreno a cobrir. A segunda é que a vastidão de cursos existentes atualmente não beneficia o extremo inferior da hierarquia social. Alcança os que estão quase na base, mas não atinge os últimos da fila. Para estes, o sistema continua oferecendo muito pouco.

No mundo empresarial, há uma clara tendência para que o número de cursos concluídos seja tão maior quanto mais elevado na hierarquia da empresa estiver o funcionário. Há algumas razões para isso. As posições mais elevadas são mais complexas, exigem mais atualização e o impacto no restante da equipe é maior.

Além disso, há rotatividade maior nas posições mais baixas, agravada por instituições hoje inadequadas à dinâmica do mercado de trabalho. Por essa razão, empresas não investem ou investem muito menos do que poderiam em funcionários 
cuja probabilidade de abandonar a firma é mais elevada, e essa ação, por sua vez, afeta negativamente a formação dos jovens e dos mais pobres.

Em suma, a sociedade, corretamente, valoriza os méritos da educação como ferramenta para a produtividade e como mecanismo de mobilidade social. Diante disso, vão sendo forjados filtros que selecionam as pessoas em função do seu capital humano. Mas esses mesmos filtros que premiam aqueles que têm mais escolaridade punem os que não a têm. Portanto, a educação tanto é um fator de mobilidade - para os que a tem quanto de exclusão - para os que não a têm.

Melhorar a educação básica é um imperativo econômico, pois as empresas precisam de gente mais educada. Mas é também um imperativo social, uma vez que a mobilidade social hoje depende de boas escolas. Em outras palavras, não há aqui uma contradição entre os objetivos de equidade e os objetivos de crescimento econômico. As políticas que promovem um são as mesmas que promovem o outro.

\section{Educação Inclusiva - Teoria X Prática}

A educação inclusiva está respaldada por normas, leis, portarias. Isto é, a teoria indica um sistema com ambiente físico favorável, materiais didáticos de qualidade, respaldo aos educadores, capacitação para os profissionais em particular para proporcionar um atendimento qualitativo através do respeito as desigualdades dos sujeitos, porém se faz necessário avaliar como se concretiza a prática, as carências e resistências dos que fazem parte do processo.

A literatura declara que desde a implantação da reforma, que aconteceu de forma abrupta, imposta, sem ter 0 investimento na formação dos profissionais da educação e não fazer um estudo no impacto que essa inclusão provocaria na vida dos alunos, familiares e profissionais, verifica-se que não houve um grande avanço no investimento do preparo dos profissionais do ensino regular, como afirma Angelucci (2002) são “vários educadores que procuram, com muitas dificuldades, trabalhar de maneira ética e comprometida com a Educação Pública, bem como manter a sua dignidade e a dos usuários das escolas" (p. 11), ou seja, “o poder público não está cumprindo bem sua função, o que não impede que cada um assuma sua parte e se torne sujeito dessa história" (MENDES, 2006, p. 16).

Não é possível negar que a educação inclusiva se trata de uma evolução na construção de um ambiente democrático. De acordo com Angelucci (2002) é “a maneira como muitas das políticas públicas são formuladas e implantadas, sem 
considerar a construção coletiva e democrática das diretrizes de Educação" (p. 6), o que terminar por impedir, afinal não é permitido enxergar uma transformação na prática educacional sem ocorrer questionamentos entre os envolvidos.

Conforme Sá (2003) existem dificuldades e limitações acerca da inclusão, de um lado estão os professores do ensino regular que relatam a dura realidade das condições de trabalho, o número elevado de alunos por turma, a rede física inadequada e os limites da formação profissional. Por outro lado, os pais que preferem manter os filhos em instituições especializadas por receio da discriminação no ensino regular. Apesar disso é possível constatar mudança de postura, de concepções e atitudes por parte de educadores, pesquisadores e do público em geral, pois essas diferenças já foram incorporadas como atributos naturais da humanidade. Ainda segundo Sá (2003):

Trata-se, portanto, de propor ações e medidas que vise assegurar os direitos conquistados, a melhoria na qualidade da educação, o investimento em uma ampla formação dos educadores, a remoção de barreiras físicas e atitudinais, a previsão e provisão de recursos materiais e humanos entre outras possibilidades. (p.3).

A Declaração de Salamanca (1994) afirma que a questão principal para o sucesso das instituições educacionais inclusivas, é que todos os professores possuam uma preparação condizente. Ao mesmo tempo, sugere que os educadores na formação inicial recebam orientação positiva frente à deficiência, que tenham capacidade de avaliar as necessidades especiais, adaptação do conteúdo curricular, capacidade de recorrer às tecnologias, individualização de procedimentos pedagógicos e trabalhar em conjunto com especialistas e pais.

A avaliação precoce da deficiência é muito importante, pois possibilita o início do trabalho com o aluno bem mais cedo. A realidade é diferente, o diagnóstico é demorado e isso dificulta o trabalho junto ao aluno e a família, que muitas vezes não admite o problema do filho, e o processo para sensibilização é lento atrasando mais ainda $\mathrm{o}$ atendimento.

A adaptação do conteúdo curricular é uma das estratégias que devem ser utilizadas para proporcionar a inclusão, visto que os alunos não são iguais, como afirma Marchesi (2004):

Os alunos são diferentes em seus ritmos de aprendizagem e em seus modos pessoais de enfrentar $o$ processo educacional e a construção de seus conhecimentos. A atenção às diferenças individuais educativas faz parte também de todas as estratégias educativas que se assentam no respeito à individualidade de cada 
aluno. Um respeito que, no caso dos alunos com necessidades educativas especiais, exige que se proporcione uma educação adaptada às suas possibilidades (p.38)

Para decidir em quais aspectos deve sofrer a adaptação é necessário que os envolvidos no processo conheçam as peculiaridades de cada aluno, pois as adaptações podem acontecer quanto aos objetivos de cada área, os critérios de avaliação ou quanto aos métodos pedagógicos. Essa é uma decisão criteriosa, difícil e deve ser tomada com muita responsabilidade, para tanto os envolvidos devem estar seguros. Como afirma Prieto (2006) à formação dos professores deve possibilitar-lhes analisar os domínios de conhecimentos atuais dos alunos, para que sejam capazes de elaborarem atividades, criarem ou adaptarem materiais $\mathrm{e}$ aprimorem o atendimento aos alunos. Nesse sentido, Blanco (2004) considera que:

É preciso assegurar que o currículo da escola seja o mais amplo, equilibrado e diversificado possível. As equipes docentes devem fazer uma análise profunda do currículo oficial para verificar em que medida as necessidades dos alunos são contempladas para tomar as decisões adequadas (p.292).

Outro ponto que vale destacar é o uso das tecnologias como ferramenta metodológica para auxiliar o trabalho docente. É necessário um profissional com capacidade de fazer uso dessas tecnologias, para tanto como afirma Lima (2007), o mesmo deverá receber formação adequada para que suas habilidades estejam sempre à disposição da melhor forma possível ao educando. Os cursos de atualização tecnológica, além de capacitar o professor serve também como uma injeção de ânimo e motivação para que esteja sempre apto a desenvolver sua função da melhor forma possível.

O professor é a peça principal para fazer com que a inclusão realmente aconteça, portanto é necessário que ele se sinta habilitado para atuar com competência junto aos alunos. Ele não pode se sentir sozinho necessita ser amparado e orientado para agir com segurança. Nesse processo de apropriação das habilidades didáticas é fundamental destacar a atuação dos professores de apoio, conforme afirma Marchesi:

Seu papel principal é colaborar e ajudar os professores de classe para que desenvolvam estratégias e atividades que favoreçam a inclusão dos alunos com necessidades especiais. Sua tarefa, portanto, não se centra mais no atendimento exclusivo a esses alunos, mas em ajudar os professores a resolver os problemas e a encontrar a melhor alternativa para a instrução de seus alunos (2004, p.42). 
É importante considerar a participação da família da criança com necessidades especiais em seu processo de inclusão, pois sem dúvida, essa criança requer mais cuidados ao longo do seu desenvolvimento e a família necessita de adaptação e orientação de diversos especialistas. Segundo Paniagua (2004), a estimulação desde cedo, as atividades de lazer, situações de jogo ou de estudo compartilhado, requer mais tempo de interação, o que acarreta aos pais tempo para adaptarem, reorganizarem-se e ajudarem adequadamente os filhos e darem apoio necessário ao professor no processo de aprendizagem do filho.

Ao longo do processo o professor tem a possibilidade de construir o seu saber, nos debates com os colegas para troca de experiências, nos desafios vividos a cada dia, nos cursos de atualização, ou seja, o professor deve estar em formação permanente, e esse aperfeiçoamento se faz de diversas formas e em lugares diferentes, de acordo Dal-Forno e Oliveira (2004), “a inclusão é a novidade que veio para nos fazer pensar que não estamos prontos, formados, e que sempre temos algo para aprender" (p.3), portanto os educadores não poderão se acomodar, terão que discutir e participar do processo de inclusão e fazer a diferença.

\section{Formação Pedagógica no ambiente inclusivo}

O processo de mudança que passa $o$ sistema educacional, onde o objetivo é a inclusão, a formação dos professores tem sido apontada como um dos principais elementos, no sentido de assegurar a esses alunos um ensino de qualidade. Como afirma Marchesi (2004), é muito difícil avançar no sentido das escolas inclusivas se os professores em seu conjunto, não adquirem uma competência suficiente para ensinar a todos os alunos. Esse conhecimento não pode ser exclusivo dos especialistas em educação especial, é necessário que todos os envolvidos no processo tenham conhecimentos e habilidades para participar da adequação curricular, elaborar estratégias diferenciadas, superar os desafios diários e intervir junto ao aluno buscando alternativas para sanar as dificuldades.

Recentemente tem-se discutido se as instituições formadoras estão realmente preparando os professores para receber em suas salas de aula muitas vezes repletas de alunos com diversos problemas, seja de indisciplina ou conflito familiar o que acarreta dificuldade na aprendizagem, os alunos com necessidades especiais. Segundo Moreira: 
ultrapasse a linearidade e a simplificação curricular de que basta uma disciplina sobre a área da NEE para formar professores capacitados a atuarem com o alunado que apresenta dificuldades mais específicas (2007 p.268).

As pesquisadoras Ribeiro, Cordeiro e Bastos (2007), partiram da premissa de que "a maioria dos cursos de formação de professores pouco contribui para que a prática do docente se modifique em relação aos estudantes que tem algum tipo de necessidade educacional especial". É preciso que essas instituições reformulem o currículo e incorporem novas práticas de forma a possibilitar aos docentes a apropriação das habilidades necessárias para lidar com os desafios dessa nova realidade. Não basta obter conhecimento acerca da disciplina que irá trabalhar, é necessário que o profissional se sinta seguro, com domínio de estratégias para solucionar conflitos, criatividade para fazer

\section{METODOLOGIA}

\section{Características da pesquisa}

Trata-se de uma pesquisa bibliográfica com intensa leitura dos textos e obras, sistematizado por Lessa (2011, p. 20 e 21) "A leitura imanente consiste na decomposição do texto em suas unidades significativas mais elementares: ideias, conceitos, categorias, na busca da trama que articulava tais unidades a uma teoria, adaptações da metodologia e assim fazer da sala de aula um espaço de desenvolvimento. Como afirma Dal-Forno e Oliveira (2004 p. 5), “é na prática que os saberes são colocados a prova, é nela que adquirem validade ou não".

Sabe-se que existem leis que asseguram ao professor a capacitação para atuar na educação inclusiva, mas como afirma Coelho (2010 p.58) "as questões legais aparecem como suporte orientador e indutor de mudanças, mas não como garantia efetiva da inclusão, já que por si só, leis não garantem mudanças". A reformulação de cursos de graduação, investimento em capacitação e de especialização em Educação Inclusiva merece maior atenção das autoridades competentes. Não se pode delegar ao professor toda a responsabilidade de promover a inclusão dos alunos com necessidades educacionais especiais.

hipóteses, teses e proposições, com o intuito de elaborar outras teorias interpretativas".

A Leitura Imanente é um recurso que nos ajuda em estudos sistemáticos de pesquisas acadêmicos, encontrados em forma de livros, teses, dissertações, monografias, artigos, entre outros; bem como em estudos bibliográficos. A utilização e aplicação consecutiva e crítica desta metodologia aperfeiçoa o campo 
cognitivo que abrange a compreensão e a apreensão dos elementos que estruturam os modos de exprimir e materializar os conhecimentos científicos (BEZERRA, 2015).

De acordo com Vieira (2006, p. 17), “a pesquisa bibliográfica fundamenta-se principalmente em análises qualitativas, baseadas em conhecimentos teóricoempíricos que permitem atribuir-lhes cientificidade".

\section{Do ponto de vista dos objetivos}

No que diz respeito aos meios, em relação à abordagem dos objetivos, esta pesquisa é exploratória, que tem a finalidade de proporcionar familiaridade com o problema, tornando-

De acordo com o autor acima citado o primordial objetivo da pesquisa exploratória deve ser o aprimoramento das ideias ou a descoberta das instituições.

\section{RESULTADOS E DISCUSSÕES}

A educação inclusiva está relacionada ao direito à educação e, de acordo com Monteiro (2004) precisa encontrar-se em princípios como: a conservação da dignidade humana, a procura da identidade e o exercício da cidadania.

Conforme Macedo (2005) é necessário pensar a respeito dos respaldos
Do ponto de vista dos procedimentos técnicos e da abordagem do problema

As metodologias técnicas utilizadas para este estudo foi o levantamento bibliográfico e documental tem por objetivo proporcionar familiaridade com $\mathrm{O}$ problema, tornando-o mais explicitado (LAKATOS; MARCONI, 2001).

Por meio das pesquisas realizadas, de modo sistematizado, em livros, artigos científicos, disponíveis em documentos impressos e também em bases de dados virtuais reconhecidas, foram possíveis expandir o conhecimento em torno dos temas que cercam este estudo, ajudando deste modo para uma fundamentação teórica capaz de embasar a procura para atender aos objetivos propostos e responder de modo eficaz o questionamento da pesquisa.

da educação inclusiva, buscar conhecimento e refletir a maneira de funcionamento institucional, atualmente ajustado na concepção da exclusão em prol da inclusão.

Está contido na Cartilha da Inclusão dos Direitos das Pessoas com Deficiência, que para o sujeito possuir realmente uma instituição escolar democrática, é necessário estabelecer uma inédita camada social, na qual a inclusão seja total no 
mundo dos direitos e deveres (GODOY, 2000).

De acordo com Mantoan (2005) para que ocorra um projeto educacional inclusivo é preciso que aconteçam transformações nas propostas educacionais na maior parte das instituições de ensino, a reorganização curricular pensada e colocada em prática por educadores, gestores, pais, educandos e toda a sociedade participativa.

Para Pietro (2006), a inclusão é uma oportunidade independente se portador ou não de necessidades especiais; ensinar significa assinalar um encontro com o outro, e a inclusão escolar incide, de modo basilar, uma transformação de conduta frente ao outro, sendo este outro alguém de suma importância e que exige que o professor vá além.

Estabelecer um PPP, num ponto de vista de escola inclusiva decreta, assim: rever intensamente o currículo nos mais distintos aspectos, desde a disposição das classes, a seleção do educador para cada sala, o horário das aulas, a escolha de teores culturais, que na instituição de ensino recebem a denominação de conteúdos

\section{CONSIDERAÇÕES FINAIS}

As determinações emanadas na LDB 9394/1996 (Lei Diretrizes e Bases da Educação) e no Plano Nacional de pedagógicos, a seleção dos recursos didáticos, dos métodos e didáticas ao feitio de analogias que ocorrem na sala de aula e no ambiente fora dela, a afinidade da instituição de ensino com a família dos educandos e com a comunidade em que está inserida e, inclusive rever o modo avaliativo e suas consequências na vida dos educandos.

A nova orientação curricular induz a um inédito PPP guiado por um olhar além da cultura, que abranja as etnias, ajudando deste modo a tornar a instituição de ensino se concretize como uma escola includente, sintonizada com um projeto de sociedade mais democrática e, portanto, includente (GARCIA, 2003). Freire (1997) afirma que uma das qualidades do professor democrático é ter aprendido a ouvir as diversas vozes com suas expressões singulares, edificadas frente a sua realidade sociocultural, o que sugere em saber emudecer, se encontrar mergulhado na experiência histórica e real dos alunos, porém jamais mergulhado de modo paternalista, de maneira a dizer por eles mais que ouvi-los.

Educação definem que a instituição de ensino se estruture através de atos e providências de recursos indispensáveis para garantir a ascensão e permanência de todos os educandos, disponibilizando um 
ensino que leve em consideração as características do educando.

A pedagogia inclusiva é uma foto consumado em distintas cidades brasileira, em especial no estado de São Paulo, frente a escolha de descentralizar o ensino, constante na Constituição de 1988. Com o ensino passando a ser responsabilidade do município, as diretorias e secretarias Municipais de Educação vêm tentando adequar-se às Novas Diretrizes da Educação Especial na Educação Básica (BRASIL, 2001).

Em nosso país esse assunto é tratado de modo legal através dos Parâmetros Curriculares Nacionais: Adaptações Curriculares, conforme anunciado anteriormente.

\section{REFERÊNCIAS}

ARANHA, M. S. F. Inclusão social e municipalização. In: MANZINI, E. J. Educação especial: temas atuais. Marília, SP: Unesp: Marília Publicações, 2003.

BLANCO, Rosa. A atenção à diversidade na sala de aula e as adaptações do currículo. In: Desenvolvimento Psicológico e Educação: Transtornos de desenvolvimento e necessidades educativas especiais. Editora Artmed, Porto Alegre, 2004.

BRASIL. Coordenadoria Nacional para Integração de Pessoas Portadoras de Deficiências. Declaração de Salamanca e Linhas de Ação sobre Necessidades
A terminologia adaptação permite ser entendida como um modo flexível, visto que pressupõe a existência de alterações e/ou modificações no processo educacional, especialmente no sentido curricular. Para tal, o currículo necessita ser visto como referencial no reconhecimento de prováveis mudanças em razão de carências especiais dos educandos. Ou seja, a escola precisa adotar a mesma conduta curricular para os alunos em geral e, ocorrendo necessidade, realizar adaptações, alterações.

É função da equipe técnico pedagógica, incluindo o professor da sala comum, efetivar o levantamento das particularidades educacionais, demanda educacional que necessita de ajustes no currículo e propor o manejo das condições adequadas para que isso ocorra.

Educacionais Especiais. Brasília: MEC, 1994.

BRASIL. Educação Especial: deficiência mental. Org. Erenice Nathalia Soares de Carvalho. Brasília: MEC/SEESP, 1997 (Série Atualidades Pedagógicas 3).

BRASIL, Ministério da Educação. Diretrizes nacionais para a educação especial na educação básica. Secretaria de Educação Especial - MEC; SEESP, 2001.

BRASIL. Secretaria de Educação Fundamental. Parâmetros curriculares nacionais: Adaptações Curriculares / Secretaria de Educação Fundamental. Secretaria de Educação Especial. Brasília: MEC /SEF/SEESP, 1998. 
Constituição da República

Federativa do Brasil. Brasília: Senado

Federal, 1988.

. Senado Federal. Declaração

Mundial de Salamanca e Linhas de ação

sobre Necessidades Educativas Especiais:

acesso e qualidade. Brasília: CORDE, 1994.

Secretaria de educação

Especial. Conjunto de materiais para a capacitação de professores; necessidades na sala de aula/Secretaria de Educação Especial; tradução, Ana Maria Isabel Lopes da Silva. Reimp. Brasília: MEC/SEESP, 1998.

. Ministério da Educação e do

Desporto. Lei de Diretrizes e Bases da Educação Nacional. Brasília: Ed. do Brasil, 1996.

MARCHESI, Álvaro. A Prática das escolas inclusivas. In: Desenvolvimento Psicológico e Educação: Transtornos de desenvolvimento e necessidades educativas especiais. Editora Artmed, Porto Alegre, 2004.

PERRENOUD, Philippe. A prática reflexiva no ofício de professor: profissionalização e razão pedagógica. Tradução de Claúdia Schilling. Porto Alegre. Artmed, 2002.

PRIETO, Rosângela Gavioli. Atendimento escolar de alunos com necessidades educacionais especiais: um olhar sobre as políticas públicas de educação no Brasil. In: Inclusão Escolar: Pontos e contrapontos. Summus Editorial, São Paulo, 2006.

SALAMANQUE. Educação Inclusiva - um processo e um desafio. Em "Salamanque Cinq ans après" - Rapport sur les activités de l'UNESCO à la lumière de la Déclaration de Salamanque et du Cadre d'Action - pp 9-10, Tradução Jorge Santos, 2008. 